\title{
Entrevista a Mário Cláudio
}

José Cândido de Oliveira Martins

Universidade Católica de Braga, Braga / Portugal

martins.candido@gmail.com

Recebido em 30 de maio de 2018 Aprovado em 17 de setembro de 2018

JCOM: Uma das fortes e constantes presenças na sua obra parece-nos ser a reflexão sobre a cultura portuguesa, reflexão esta que propõe, ao mesmo tempo, uma indagação sobre o próprio fazer literário. Há fatores específicos que o levaram a tamanho interesse pelas questões históricas e identitárias portuguesas?

MC: Realmente, eu entendo que é muito difícil para um escritor ignorar as suas raízes. Há um risco grande, que muitas vezes se corre, admito que se possa fazê-lo. Mas os escritores que eu admiro, aqueles que tenho por mestres, têm sempre por trás um país, uma cultura, uma civilização, um enquadramento geográfico, político, etc. Portanto, o que me interessa a mim é que os meus livros tenham corpo, e o corpo é isso, é dado justamente por esse elemento. A minha escrita é uma escrita sensual, que faz apelo constante aos cinco sentidos. E eu não consigo entender esse apelo, não consigo senti-lo a não ser através desse quadrou ou desse cenário. Cenário que tem a ver com todo o meu percurso biográfico, por lado; e também com o percurso biográfico das pessoas que me marcaram e fazem parte da história cultural deste país, e não apenas deste país, mas também da Europa e, de alguma forma, do mundo. Portanto, todos estes fios acabam por tecer uma manta ou terreno em que eu me movimento. 
E faço-o de uma forma natural, espontânea, não andando propriamente à procura de dados nas enciclopédias, mas apropriando-me deles quando eles vêm ter comigo. Lembro-me de a Agustina [BessaLuís] me ter dito uma vez que tinha dificuldade de escrever um romance sem imaginar uma cidade por trás, uma espécie de cenário. Comigo acontece a mesma coisa, mas não é só uma cidade, é todo um contexto histórico-geográfico e antropológico, como disse há pouco, em que eu me enquadro, que faz parte daquilo que eu sou; ou que exerce algum fascínio sobre mim, que me interpela. Portanto, é fundamentalmente isso que lhe posso dizer a esse respeito.

JCOM: Nessa postura, conscientemente ou não, Mário Cláudio afasta-se de outros autores portugueses contemporâneos que constroem ficções com espaços e personagens propositadamente estrangeiros.

MC: Aí há, quanto a mim, vários fenómenos que podem ser lidos de maneiras diferentes. Por um lado, há esse carácter extremamente imitativo da nossa literatura, que vive na dependências das literaturas exteriores, o que aponta por vezes para um certo raquitismo cultural, a que as pessoas não conseguem sobrepor-se. Têm de ir buscar aos outros aquilo que não encontram nelas próprias. Por outro lado, há pessoas que talvez suponham, sobretudo os mais jovens, que assim lhes abra um mercado internacional, que de outra forma - falando de Portugal - dificilmente se lhes abriria. É conhecida a atitude das editoras estrangeiras, mesmo das europeias, quando dizem - "Nós não precisamos de autores portugueses, porque já temos o Saramago, e Portugal é um país muito pequeno".

Isto é vulgar no discurso de aproximação às editoras. Eu acho que essa aposta na internacionalização é sempre uma aposta arriscada e perigosa. Escrever com vista a ser traduzido é uma atitude de grande imaturidade, para mim, desde logo de imaturidade cívica e de imaturidade intelectual. O que eu entendo é que as obras que possam eventualmente vir a ser traduzidas - justamente porque são de autores portugueses e que criaram a ficção de que têm de ser iguais aos estrangeiros -, não têm originalidade e acabam muitas vezes por cair no esquecimento, por serem ignoradas ou passarem a segundo ou terceiro plano.

E muito curiosa esta atitude do mundo editorial dos outros países em relação à nossa literatura porque há aqui uma constante - sempre que um autor novo aparece e se reveste de algum talento, é capaz de encontrar várias portas abertas para a tradução. Isso aconteceu comigo, grandes 
casas editoras abriram as suas portas para o meu livro Amadeo. Mas o problema é este: esses livros vendem muito pouco, porque são livros, no meu caso, que reflectem uma cultura periférica, em relação aquilo que é o mainstream europeu. Mas também quando fazem também a tal tentativa de escrever uma espécie de blue jeans literário, que serve para tudo, em todos os tempos e lugares, também acabam por não ir a parte nenhuma.

Portanto, eu acho que escrever em Portugal sobre Portugal é não apenas um dever, mas também uma garantia de autenticidade. Aliás, basta pensarmos em algumas grandes figuras da literatura do séc. XX: não podemos pensar em Proust sem Paris ou a França; é inconcebível, um Tolstoi ou um Dostoievsky sem a Rússia; um Joyce sem a Irlanda; uma VirginiaWolf sem a Inglaterra, um Musil sem Viena ou sem a Áustria; etc. Estes autores não fizeram literatura para serem internacionais; fizeram aquilo que era a literatura possível, e a literatura natural, no espaço em que eles se movimentavam.

JCOM: Pode-se dizer que boa parte de sua obra em prosa lança mão de textos e de mitos que pertencem à memória cultural do Ocidente, em um processo que os transforma em um "outro" que acaba por se constituir, por assim dizer, em uma notável reflexão sobre a condição humana. Como é que funciona esta sua oficina, este seu laboratório de recriação da matéria histórica e cultural? Melhor dizendo, como é o seu método de trabalho e de leitura?

MC: Quando me falam nisso, eu tenho que me situar imediatamente naquilo que eu julgo que é o meu habitat natural, que é a cultura europeia. Eu sou antes de mais nada um europeu, marcado pela tradição greco-latina, e também pelos apports que depois foram dados pelo Renascimento e pela cultura do Humanismo; e, mais tarde, pelo Romantismo, pelo Realismo, por exemplo, que são movimentos de origem europeia. Portanto, é nessa cultura que eu me movo. É natural por isso que os mitos e as grandes figurações dessa cultura estejam presentes em mim quando escrevo.

Não posso ignorar a importância de uma figura como Prometeu, ou os heróis da Ilíada e da Odisseia. Como não posso ignorar o contributo cultural de Leonardo Da Vinci. Nem é possível ignorar figuras do Romantismo inglês, como as irmãs Brontë. Ou, mais próximos de nós, figuras da cultura portuguesa como Aquilino Ribeiro, Tomaz de Figueiredo ou Agustina Bessa-Luís. São essas figuras que constituem 
uma cadeia na qual eu me integro, não por escolha, mas naturalmente, como forma de estar e de ser.

JCOM: Na sua escrita ficcional deparamo-nos com imensas figuras literárias de escritores - de Luís de Camões e de Camilo Castelo Branco até Eça de Queirós a Fernando Pessoa (Bernardo Soares), e de artistas Amadeo de Sousa-Cardoso, Rosa Ramalho e Guilhermina Suggia-, entre outros nomes portugueses e estrangeiros. Porquê esta atracção ou mesmo fascínio pela biografia e obra destas personalidades, convocadas por um desejo de reescrita, em que se reinventam essas figuras? Como estas vidas se cruzam com a do escritor e lhe motivam a vontade de escrever?

MC: São tudo figuras que se inserem no habitat cultural de que eu falava há pouco. Há figuras que vêm ter comigo, ou por estarem mais próximas, naturalmente, como as referidas da cultura portuguesa. $\mathrm{Ou}$ por serem figuras de tal forma tutelares, em termos de influência cultural exercida (como Leonardo Da Vinci, Lewis Carrol, etc.), que são figuras que acabam por fazer parte do meu círculo de amigos, de interlocutores próximos, de pessoas com quem eu dialogo. $\mathrm{E}$ isso acontece naturalmente também, não ando à procura delas, elas é que vêm ter comigo. De repente, impõem-se como presenças, como encarnações, digamos, que num momento ou noutro se tornam absolutamente vitais para mim e sobre as quais eu tenho necessariamente de falar. É uma selecção natural, é o que vem ao meu encontro.

JCOM: Isso não significa necessariamente que foram essas figuras que mais o marcaram como escritor - tome-se o caso de Fernando Pessoa.

MC: Pessoa é uma figura para mim muito mais interessante como caso do que propriamente como poeta. Algumas pessoas ficam um pouco arrepiadas quando eu digo isso, mas para mim o caso poético de Pessoa reveste-se de uma relevância romanesca rara - a questão dos heterónimos, o drama em gente, tudo isso. É uma porta aberta para se falar dele, independentemente daquilo que ele escreveu. Agora, daquilo que ele escreveu, há coisas que eu aprecio e outras de que não gosto tanto. Por exemplo, não me sinto tão atraído pelo racionalismo de Alberto Caeiro, mas antes pelo sensualismo do Álvaro de Campos. Mas isso aí são questões já de carácter temperamental e de afinidades pessoais, que me levam a sentir-me muito mais da família de um Proust do que de um Musil. 
JCOM: E aproxima-se destes autores antes referidos sem venerações excessivas.

MC: Sim, claro, todos eles têm as suas fragilidades. Ainda há dias escrevi qualquer coisa sobre isso, a propósito daquela tenção eterna entre Camilo Castelo Branco e Eça de Queirós. O Eça conseguiu fazer uma coisa curiosa - introduzir na literatura portuguesa a ironia, coisa que o Camilo nunca conseguiu, caindo quase sempre numa atitude de troça, em vez de ter uma atitude propriamente de saídas ou de interpretações mais ou menos jocosas. O sarcasmo de Camilo é também uma manifestação de frustração. É a impossibilidade de ficar au-dessus de la mêlée como estava o Eça. Porque o Eça contemplava o mundo de cima para baixo; já o Camilo contempla-o de baixo para cima e vocifera.

$\mathrm{O}$ que eu acho que aconteceu foi o seguinte: as pessoas tomaram o Eça como um modelo, sobretudo como um estrangeirado que trazia aquelas elegâncias lá de fora, aquele cosmopolitismo, que existe de facto. Não é como o Pessoa diz, é espantoso que lhe chame um provinciano no seu culto cosmopolitismo. Isto dito por um homem que nunca saiu do Chiado e do Rossio, é uma coisa extraordinária. A verdade é esta: as pessoas ficaram muito fascinadas por aquilo que Eça disse, fingiram que achavam muita graça àquilo que ele disse, designadamente em relação aos tipos que ele criou e que são, de facto, uma galeria de retratos da mentalidade portuguesa, mas continuaram a ser essas figuras. Os Salcedes não deixaram de ser Salcedes, os Conselheiros Acácios continuaram a ser Conselheiros Acácios, duram até hoje. Nunca foram capazes de fazer aquilo que é fundamental para que haja uma alteração de mentalidades, que é rirem-se deles próprios, de fazer humor com eles próprios. $\mathrm{E}$ isso é, de facto, sempre fatal. Ao contrário do que acontece num país como Inglaterra, em que o humor faz parte integrante da cultura, mas começa na capacidade de as pessoas se rirem dos seus próprios ridículos. Nós nunca o fizemos, levamo-nos muito a sério sempre.

JCOM: Na sua obra literária, Mário Cláudio apresenta uma concepção bastante flexível e híbrida de géneros literários, cruzando sobretudo a biografia e o romance (biografia romanceada, por ex.), desde logo em narrativas de dimensão bastante variável, muito centradas na re-criação de determinadas atmosferas. E porquê esta inclinação para a narrativa de cariz biográfico? 
MC: Na pergunta estão vários aspectos. Primeiro, a questão do hibridismo dos géneros. No meu caso, resulta da minha natureza barroca. $\mathrm{O}$ barroco assume essa característica precisamente, é uma estética de hibridismo, de mistura de cânones, ao contrário do modelo clássico, em que há uma separação absoluta dos géneros e dessas coisas. Sendo eu formalmente um barroco, serei necessariamente no conteúdo um barroco e, portanto, essas misturas de modelos sempre existiram - um romance que é uma biografia, uma biografia que é um romance, enfim, um romance que tem um ingrediente poético ou teatral muito forte, etc. Dificuldade em distinguir biografia de autobiografia, que é constante no meu caso, tudo isso são decorrências da minha atitude barroca perante a vida.

A par disso, sobressai a minha tentação para destruir mitos, sobretudo os mitos pátrios, é uma tentação. Por exemplo, transformar o Camões num homem de carne e osso, sem dúvida um grande poeta, mas também um grande facínora, um homem com todo o tipo de defeitos que tinham os homens daquela época. E que ele tem talvez mais do que alguns, afinal um valdevinos que passou pela cadeia, chegou a ser transferido por abusar do erário público. Tudo isso foi escamoteado em função da construção da estátua de bronze, do mito. Acho que realmente o Camões teria tido uma recepção muito maior na juventude de hoje se esse lado humano fosse mais conhecido.

Camões era um homem fragilíssimo do ponto de vista comportamental, que tinha todas as fraquezas que um homem pode ter. Frequentador de bordéis, era um tipo que gostava da boa vida, das patuscadas. Não era propriamente um nefelibata que estava lá nas nuvens a tocar lira... Mas foi isso que lhe fizeram - remeteram-no ao consílio dos deuses, acharam que ele era mais um a pôr lá, e lá ficou. As representações iconográficas são também exemplares nesse sentido. E por isso, enquanto não se destruir isso, não temos o Camões, temos uma estátua. Mais uma vez, os ingleses fizeram uma coisa magnífica com Shakespeare, porque lhe apontaram todos os defeitos, todas as qualidades, chegando ao ponto de dizer que ele nunca existiu...

JCOM: Em todo o caso, Camões foi erigido em símbolo e mito da pátria portuguesa, desde logo em momentos de crise política...

MC: Rigorosamente, Camões nunca foi um homem político que lutasse por grande ideais. Era antes um homem que lutava pela sua tença, pela sobrevivência. Nós sabemos que ele adulou o rei D. Sebastião, justamente 
para ficar com algum dinheiro. Aliás, se quisermos, Camões foi um dos responsáveis por Alcácer-Quibir, pelo finispatriae na altura, porque ele incentivou o rei a ir para o Norte de África, quando poderia ter feito de outra maneira. Poderia ter tido uma atitude defensora do confronto do rei com o mundo protestante, sem sair da Europa, o que seria mais natural. Foi isso que fizeram os espanhóis. E fizeram-no tão bem que depois acabaram por nos abarbatar e nós deixámo-nos ir no jogo!

Portanto, há esse elemento na figura de Camões. Não é um defensor das liberdades, como será mais tarde um Martí[José JuliánMartí Pérez] em Cuba, ou um [Sándor] Petöfi na Hungria, que são poetas nacionais que lutaram pelas liberdades ou pela independência do país. Camões nunca o fez. Mesmo em relação a Espanha, teve sempre uma atitude duma grande duplicidade, porque escreveu em castelhano, porque não se demarcou completamente daquilo que era o mundo castelhano. Estava muito próximo de pessoas como a rainha D. Catarina, que passou a vida inteira a fazer a política do sobrinho, Filipe II. Portanto, quanto a mim, Camões não é um exemplo de patriotismo.

JCOM: Uma temática que atravessa vários dos seus livros é a presença do sagrado e do religioso. Como explica essa presença ou esse diálogo entre o transcendente e a realidade quotidiana, entre o ético e o estético? E, já agora, como observa a pouca atenção que a crítica literária tem concedido a esta dimensão da sua escrita?

MC: É uma temática estruturante e tenho pena que as pessoas não se tenham debruçado sobre ela. Aliás, está agora a ser objecto de um estudo por parte de um jovem investigador, Martinho Soares. Há, de facto, um veio de espiritualidade que passa por um catolicismo um pouco herético, que não assimila completamente todos os dogmas, mas sobretudo que não assimila aquilo que é a prática do catolicismo, tomando posições fraturantes em relação aos ensinamentos de Roma, mesmo em termos disciplinares, etc. Isso existe na minha obra, está muito patente.

E quanto a mim, eu vejo aí a qualidade do europeu, como antes falámos, porque é de facto a tradição judaico-cristã que está presente, e não é outra - como aconteceu com muitos escritores europeus, sobretudo do Norte da Europa, que se deixaram fascinar pelas filosofias orientais e com resultados extraordinários. Eu não poderia enjeitar essa tradição judaico-cristã, mas também não posso de maneira nenhuma considerar 
isso assimilado por mim ou refletido de uma forma particularmente visível na minha obra.

Também acho que há religiosidade na escrita de outros autores que tem sido escamoteada, por exemplo na obra de Agustina. Porque nós ainda vivemos à sombra daquilo que era o laicismo e o anti-clericalismo do princípio do séc. XX. Estamos ainda muito marcados por isso, Portugal mais do que qualquer outro país. É engraçado que isso se manifeste ao nível dos católicos. Aliás, o católico português é de muito má qualidade, se comparamos com o católico francês ou até com o espanhol. Estes têm uma atitude muito mais desembaraçada e sobretudo bem mais descontraída e menos preconceituosa. $\mathrm{O}$ católico português ainda tem vergonha do seu catolicismo, tem medo que lhe chamem beato ou frágil, ou que tem medo da morte, enfim, essas coisas todas. Coisas que já desapareceram há muito de um país como a França.

JCOM: Vê aí um contraste entre Portugal e outras culturas.

MC: Repare-se que nós nunca tivemos um escritor católico como um [Georges) Bernanos, um [Antoine de] Saint-Éxupéry ou um [Henri de] Montherlant. Nunca tivemos essas figuras por uma razão muito simples: os escritores de uma maneira geral tinham vergonha de assumir o seu catolicismo. Os poucos que assumiram, como é o caso de Antero de Figueiredo, Miguel Trigueiros, etc., figuras menores e pouco conhecidas, ficaram sempre envoltas num cheiro a sacristia... que não tem nada a ver com a Igreja. Agora, em Portugal, aparecem algumas figuras do seio da própria Igreja Católica que se destacam, por exemplo no campo da poesia, como Daniel Faria ou como José Tolentino de Mendonça. Lembro-me de uma vez ter falado ao Eduardo Prado Coelho no Daniel Faria e ele não o valorizou, dizendo que para si não fazia sentido alguém estar num convento a escrever poesia de qualidade. Curiosamente, depois acabou por reconhecer que era uma poesia de qualidade. Como vemos, é um processo que leva algum tempo, porque há um preconceito muito vivo, muito feroz.

A par de vários outros preconceitos existentes na literatura portuguesa. E um deles é que aquilo que é mesmo bom é o que cristalizou no experimentalismo dos anos de 60, de importação francesa - Maria Gabriela Llansol, Rui Nunes, essas e outras figuras, que não digo que não tenham a sua palavra, mas aquela estética já passou. Entretanto, houve um retour au récit, um pós-modernismo, uma quantidade enorme de 
ideias e de situações que puseram aquilo no arquivo. Mas curiosamente o mundo académico ainda fica fascinado por essas figuras, que acha serem a quinta-essência da literatura. É preciso dar atenção a outras vozes e outras maneiras de estar.

JCOM: Sendo um autor consagrado, distinguido pela crítica e pela atribuição de vários prémios literários, e também enquanto leitor, como acompanha a obra literária de outros autores contemporâneos, sobretudo mais jovens, dentro e fora de Portugal?

MC: Eu leio muita gente, faço questão de ler os novos, os livros que me mandam, mas não só. Leio também por curiosidade, por interesse, etc. E a verdade é esta: há gente a escrever com grande qualidade na geração nova, mas também com grande invisibilidade. Pouca gente os conhece, não sabem quem eles são, mesmo entre os leitores jovens. Há muitos jovens escritores, aparecidos nos últimos dez anos, que têm grande qualidade e que não têm nada a ver com aquele aluvião que invade as livrarias ou escaparates de supermercado de coisas de terceira ou de quinta categoria.

Quem disser - e há muitas pessoas que dizem isso - que a literatura actualcaiu na banalidade e na mediocridade, etc., comete uma grande injustiça. Há até mais qualidade do que havia no meu tempo, gente com real qualidade. Mais, e isto é importante que se diga: há muita gente a emergir fora da secretaria do país que é Lisboa e redondezas. Há gente a fazer até uma opção de vida fora de Lisboa, e que hoje, dadas as facilidades de comunicação e das novas tecnologias, tem uma capacidade de fazer ouvir a sua voz que não era possível há trinta ou quarenta anos atrás.

Claro que o nosso meio literário e cultural, sendo tão exíguo e com algumas fragilidades, exige algum apoio estatal para que os escritores possam divulgar-se no estrangeiro. Porém, esse apoio estatal tem sido praticamente nulo. A periferia também se manifesta nessa falta de presença cosmopolita, de presença no mundo. Em Portugal quase não existe a figura do agente literário, que é quase imprescindível para gerir a carreira dos autores. E os poucos agentes literários que existem são de má qualidade. Continuamos a ser muito débeis.

Lembro que quando se fez em Paris a iniciativa das Belles Étrangères, em que Portugal aparecia como país convidado, houve muita gente que rejubilou, dizendo que naquela momento é que as letras portuguesas iam para a frente... Perdeu-se essa oportunidade, não se ganhou nada, ninguém foi para a frente, ficou tudo como era. Depois 
há esta coisa terrível dos escritores que se destacam no estrangeiro, acontecendo isso num país, enquanto em outros são completamente desconhecidos. O Lobo Antunes, que eu acho que é um grande escritor, é muito conhecido em França, mas, por exemplo, ninguém o conhece em Itália ou em Inglaterra. Há nomes portugueses relevantes que não dizem absolutamente nada ao meio literário internacional. Durante imensos anos o influente The New York Times Book Review não publica uma única recensão a um livro de um português, o que é uma coisa espantosa.

JCOM: Há quem goste de fazer exercícios de comparação ou relação entre as literaturas portuguesa e brasileira, seja para refletir sobre os percursos e vocações que as marcam, seja para estabelecer gradações de diferença entre elas. Qual é a visão que tem hoje acerca das conexões possíveis entre a literatura atualmente produzida atualmente em Portugal e no Brasil?

MC: Acho que os autores brasileiros já foram muitos mais lidos em Portugal do que são agora. Tinham um público muito fiel, sobretudo certos grandes nomes: estou a lembrar-me, por exemplo, de Jorge Amado, Graciliano Ramos, Clarice Lispector, João Guimarães Rosa, Raquel Queirós, Erico Veríssimo, entre outros, que eram efectivamente figuras de grande culto em Portugal, uns mais populares do que outros. Era gente que escrevia muito bem, com grande qualidade, lidos com profunda admiração. Na poesia, Drummond de Andrade, Manuel Bandeira, Cecília Meireles, etc. Eram vozes muito lidas e muito apreciadas em Portugal.

Hoje o que há - e se calhar isso acontecem em todo o mundo -, neste diálogo Portugal Brasil, é que as figuras brasileiras que emergem e chegam a Portugal, rapidamente desaparecem, é tudo muito efémero. Leva um ou dois anos a falar de A, B ou C, e logo se evaporam. Seja por opções editoriais, porque as editoras não investem muito na grande literatura, com pouquíssimas excepções. Seja por esta tendência do mundo actual, em que a última coisa ou a última moda é aquela que pega momentaneamente.

Mesmo em relação àquela literatura mais massificada isso acontece. Veja-se o que aconteceu com o fenómeno sociológico Paulo Coelho, que durou algum tempo, mas hoje já ninguém fala nele. Se formos aí a um posto de gasolina não se encontram os livros de Paulo Coelho... E dantes era uma presença bem visível. Hoje, mais do que nunca, é sempre preciso dar lugar a outros, nesta lógica de mercado. 
Há um fenómeno de efemeridade muito grande, quer de presença de autores brasileiros em Portugal, quer de autores portugueses no Brasil. Não consigo encontrar isso nas grandes figuras da literatura americana, que ficam muito mais radicadas. Basta pensar em nomes como Don DeLillo, Jonathan Frenzel, PhilipRoth. São grandes figuras que mantêm uma considerável permanência entre nós.

Além disso, de um e de outro lado do Atlântico há também a tendência para a promoção de autores demasiado jovens. E também a afirmação de autores através de factoresextra-literários. Em alguns casos, beneficiando do facto de serem figuras mediáticas, o que não é necessariamente mau. Só é mau na medida em que pode ser abusado esse modelo, como aconteceu com cantores pop que escreveram livros. Mas, por exemplo, o escritor português Rodrigo Guedes de Carvalho tem sido altamente penalizado na área literária por ser um pivot de telejornal. Muitas pessoas compram um livro dele e não o conseguem ler por causa desse preconceito. Os seus livros são de uma exigência grande, muito ao contrário do que se pensa, e de forma muito diferente de alguns outros autores do mesmo meio televisivo.

Entrevista concedida a José Cândido de Oliveira Martins em julho de 2018. 